\title{
New UC ANR working group to address residual material from anaerobic digesters
}

A naerobic digestion is an increasingly popular waste management strategy in California, with over 200 facilities operating and more under construction.

Anaerobic digesters use microbes to break down organic wastes, including biosolids in treated wastewater, lawn trimmings, food wastes and manure. The digestion process produces methane-rich biogas, which can then be captured and used to generate electricity or power vehicles.

The residual solids and liquids left over after digestion is complete are known as digestates. As the anaerobic digestion sector has grown, so has the need for a coordinated strategy to manage these digestates.

Since they are rich in nutrients and organic matter, digestates are potentially valuable as soil amendments. But their composition can vary considerably and their performance has not been well documented. Better information about digestates and their potential uses could promote the development of markets for the materials, which would in turn help make digester facilities more financially sustainable by replacing digestate disposal costs with revenue opportunities.

To facilitate the beneficial use of digester residuals, Stephen Kaffka, a UC ANR Cooperative Extension

\section{Letters}

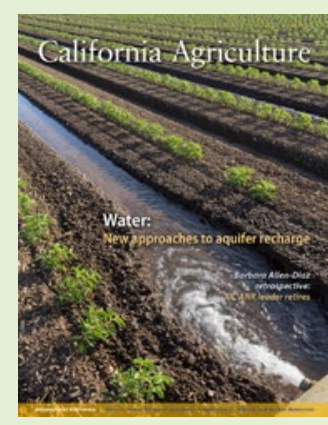

April-June 2015

\section{Re: O'Geen et al., "Soil suitability index identifies potential areas for groundwater banking on agricultural lands," California Agriculture 69:75-84:}

I believe we should also consider old approaches that at the time weren't considered aquifer recharge, but water wasted to the ground. Being raised in the Central Valley, I remember many a hot day spent swimming in cool canals carved into the soil. Then I observed the conversion of nearly all dirt-lined canals to concrete-lined canals, mostly in the name of water conservation. While probably reducing maintenance needs, this also eliminated miles (and acres) of recharge surfaces. If we could return lined canals back to earthen canals, this "old" approach could expand recharge across many portions of the state crisscrossed with canal systems. Furthermore, if the purpose of canal management could be expanded from water delivery conveyances to include water storage (i.e., kept watered year-round except during periods of maintenance), there might be enough water stored in them to obviate the need for new a reservoir or two.

Brad Valentine

Santa Rosa
I found the concept behind the article - artificial infiltration and accelerated recharge - fascinating.

Resource management looks at stormwater as an economic resource. In the climate upheavals to come, the predictions are for sudden, massive storms that shorten the infiltration intervals. The kind of flood infiltration talked about in the article tends to this direction.

I think we do need to design farms for recharge rather than drainage. Sustainable design aims at preserving the structure and function of the natural water cycle, including groundwater recharge, despite an unstable climate. Ecology tends to look at the structure and function of the natural world, and how best to preserve natural cycles is a high priority of sustainability. But this is a difficult, if not impossible, task that challenges the best of us. We need to know the natural recharge capacity of the land, and derive a realistic threshold value for recharge - what nature would do had the land remained wild and unconverted to farmland. "Ecological farming" strains my imagination, because I am not an ecologist — but I wonder if we couldn't model natural thresholds in the same manner as this article models artificial recharge. Bud Hoekstra Glencoe
RSVP

\section{WHAT DO YOU THINK?}

The editorial staff of California Agriculture welcomes your letters, comments and suggestions. Please write to us at: 2801 Second Street, Room 184, Davis, CA 95618, or calag@ucanr. edu. Include your full name and address. Letters may be edited for length and clarity. 
(UCCE) agronomist at UC Davis, and David Crohn, a UCCE specialist at UC Riverside, are organizing a new working group of more than a dozen UC ANR researchers and private-sector collaborators.

The group seeks to characterize different organic amendments and fertilizer products created from digested materials as well as to analyze and compare their performance for a wide range of agronomic and horticultural uses. Results will be made public and the information used to support the development of in-state markets for fertilizer and soil amendment products for diverse uses, as well as to develop recommendations for their safe and effective use.

The newly forming group involves academic, industry and regulatory agency participants, and is currently applying for funding through the state Department of Food and Agriculture and other sources. Kaffka and Crohn said participation by any interested ANR researchers, campus-based scientists or anaerobic digestion industry participants would be welcome.

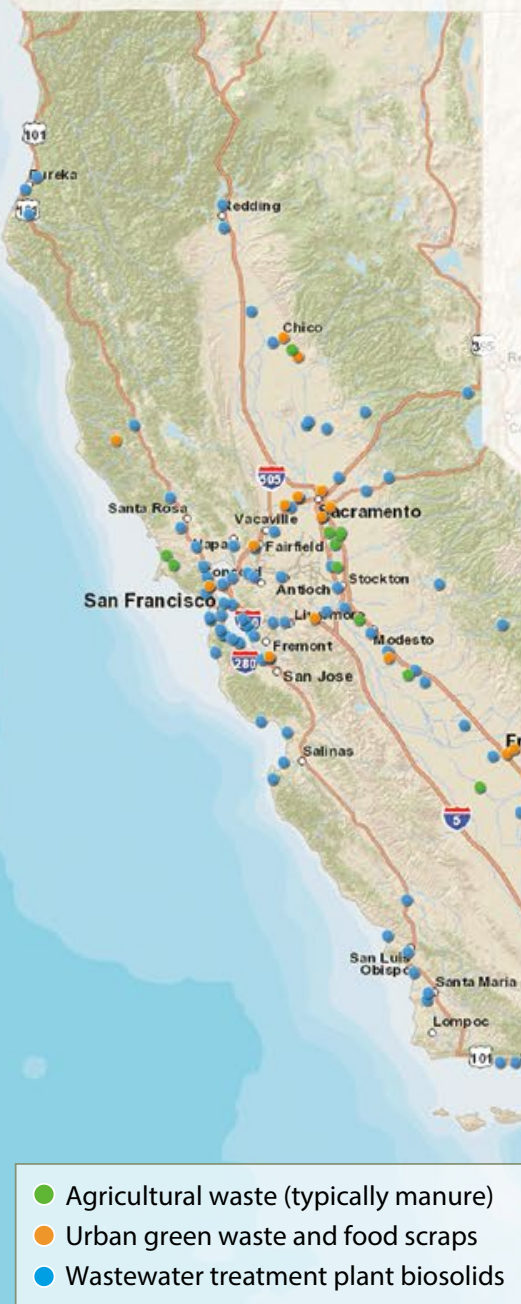

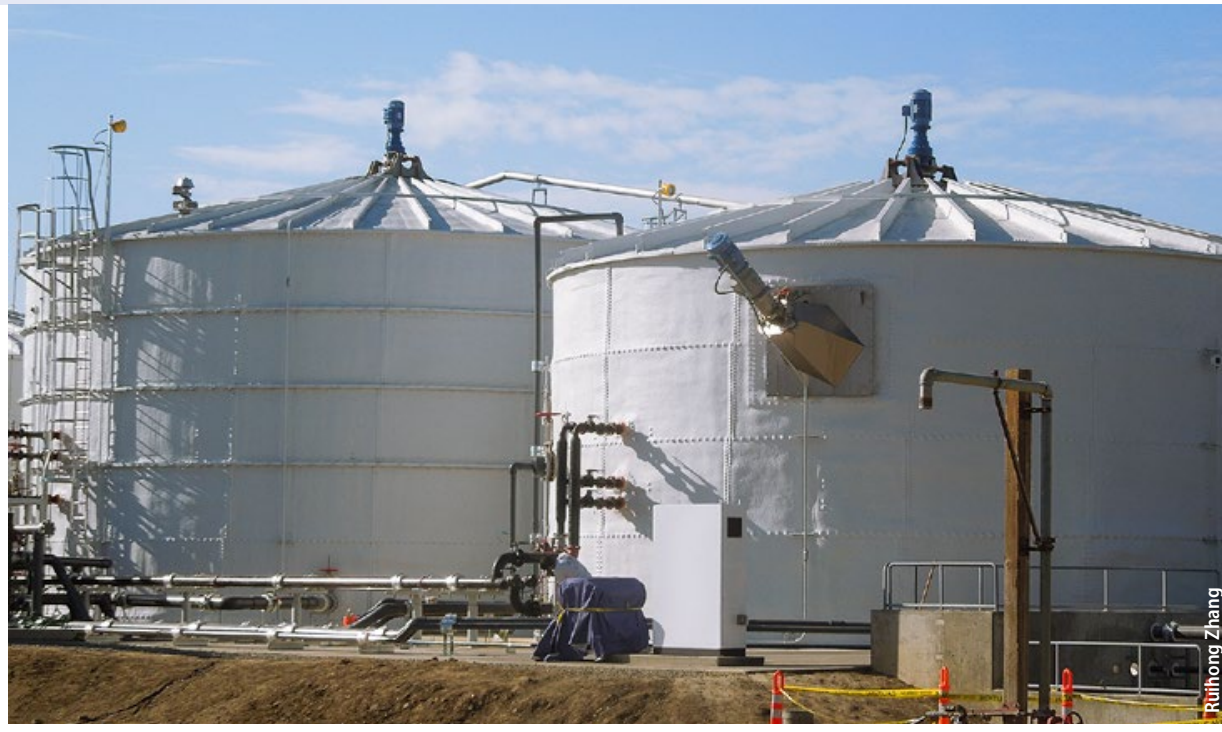

The nature of the anaerobic digestion process positions the technology well to contribute to reaching state goals for diverting organic wastes from landfills and reducing greenhouse gas emissions.

Anaerobic digestion's climate benefits are particularly striking when compared to alternative pathways for the disposal of organic matter. Decomposition in landfills or manure lagoons can release large amounts of methane to the atmosphere. Released methane is a greenhouse gas that is 34 times more potent than carbon dioxide. While many municipal landfills capture a portion of the methane generated by decomposing waste, much evades collection efforts and escapes. Some livestock operators already use anaerobic digesters or have systems to collect methane from manure lagoons, but many do not.

Compressed natural gas fuels produced from biogas are considered by California Air Resources Board staff to be among the lowest-carbon biofuels potentially available. They are by far the most climate-friendly fuels available today, with a lifecycle carbon footprint around one-tenth that of standard gasoline. Low-carbon fuels will be needed in increasing quantities to meet state targets for reducing greenhouse gas emissions from transportation.

On the UC Davis campus, anaerobic digesters break down food waste and manure and generate biogas.

$$
\text { _Jim Downing }
$$

\section{More than 200 anaerobic digestion facilities are operating in California, fed by a variety of types of biomass.}

